\title{
LA CREACIÓN LÉXICA EN LA PROSA DE SAN JUAN DE LA CRUZ: NEOLOGISMOS SUSTANTIVOS Y VARIANTES ${ }^{\prime}$
}

Rosario Domínguez

\begin{abstract}
"El castellano, como cualquiera otro idioma vivo, necesita la formación gradual y constante de voces nuevas, pues con el discurso de los tiempos y el progreso natural de las ideas van siendo insuficientes las que posee de caudal primitivon ${ }^{2}$.
\end{abstract}

Sabido es que uno de los procedimientos más fructíferos de la formación de nuevas palabras consiste, sin lugar a dudas, en la derivación sobre voces ya existentes.

El hombre de la calle en sus conversaciones cotidianas ha creado, crea y seguirá creando, aunque la mayoría de las veces de una forma inconsciente, gran número de términos que no se registran en los diccionarios. Pero esas invenciones están condenadas al olvido, a no ser que una serie de circunstancias concurra para que la colectividad las asuma como propias, incorporándose al repertorio lingüístico. No ocurre así con nuestros escritores: la fuerza de la pluma, la persistencia del lenguaje escrito hacen que sea la suya una posición privilegiada; sus creaciones individuales, si no se suman al acervo de la lengua, al menos persisten en el papel como testimonio. Dice a este propósito Baldomero Rivodó:

'Este estudio se enmarca dentro de un proyecto de investigación patrocinado por la C.I.C.Y.T. sobre El léxico técnico de la espiritualidad en el Siglo de Oro, dirigido por la profesora Doña M.* Jesús Mancho Duque.

${ }_{2}$ Baldomero Rivodo, Voces nuevas en la lengua castellana, París, Librería de Garnier Hnos., 1889, p. 2. 
' "Obsérvese que autores de nota se han servido frecuentemente de voces que no están en el Diccionario o que no lo estaban en la época en que ellos escribieron» ${ }^{3}$.

Valga este brevísimo apunte para centrar el objetivo primordial de nuestro trabajo: destacar la figura de San Juan de la Cruz como verdadero artífice del idioma, a través del estudio de un conjunto de vocablos empleados por él que, sin embargo, no encontramos recogidos ni en los diccionarios más cercanos a la época: el Tesoro de Covarrubias y el Diccionario de $A u$ toridades, ni en el Diccionario Critico Etimológico Castellano e Hispánico ${ }^{4}$.

El potencial innovador de su escritura se manifiesta, sobre todo, en el plano léxico y, de un modo muy especial, en la formación de términos neológicos. Para ello se servirá, como es lógico, de los recursos que le ofrece el sistema $\mathrm{y}$, dentro de éstos, del más productivo: las reglas derivativas. Pero el Santo no se conforma sólo con ir más allá de lo normativo; con frecuencia la mera creación léxica le resulta insuficiente para expresar la inefabilidad de su experiencia y, así, confiere a las nuevas palabras un sentido muy específico, que queda configurado de manera precisa en el contexto místico. Su creatividad se extiende, pues, tanto al plano morfológico como al semántico, es decir, abarca plenamente las dos caras del signo lingüístico: la exterior (el significante) y la interior (el significado).

${ }^{3}$ Baldomero Rivodo, Voces nuevas..., op. cit., p. 4.

4 Sebastián de Covarrubias, Tesoro de la lengua castellana o española, Barcelona, Alta Fulla, 1987, (citaremos en adelante Covarr.).

Real Academia Española, Diccionario de Autoridades, Madrid, Gredos, 1984, (en adelante $A u t$.).

J. Corominas y J. A. Pascual, Diccionario Critico Etimológico Castellano e Hispánico, Madrid, Gredos, 1986, (en adelante $D E C H$ ).

Tampoco aparecen en los siguientes repertorios léxicos: Luis MARTy CABallero, Vocabulario de todas las voces que faltan a los diccionarios de la lengua castellana, Madrid, Imprenta de don Anselmo Sta. Coloma, 2.* ed., 1859.

Baldomero Rivodo, op. cit.

Francisco Rodriguez Marín, Dos mil quinientas voces castizas y bien autorizadas que piden lugar en nuestro léxico, Madrid, Tipografía de la "Revista de archivos, bibliotecas y museos», 1922.

M." Lourdes García Macho, Aportaciones al Diccionario Crítico Etimológico Castellano e Hispánico de Joan Corominas y José A. Pascual, Lovain-la-Neuve, Travaux de Sémantique et Herméneutique, 1986.

Hay que tener en cuenta, no obstante, que algunas de esas voces se han incorporado con posterioridad a la norma y hoy forman parte del corpus léxico, como demuestra el estar registradas actualmente en el Diccionario de la lengua española de la Real Academia Española, vigésima ed., Madrid, Espasa-Calpe, 1984, (en adelante DRAE). 
Dentro de los neologismos sanjuanistas ${ }^{5}$ nos vamos a ocupar de los sustantivos verbales (o deverbales -esto es, de aquellas formas sustantivas creadas a partir de verbos latinos o romances- puesto que constituyen un corpus relevante en su obra y nos permitirán llegar, creemos, a alguna conclusión de interés.

\section{ESTUDIO DE ESOS SUSTANTIVOS ${ }^{\circ}$}

Se trata de sustantivos que derivan de una base verbal por medio de los sufijos: -miento $(\leftarrow$ ment -$)$, —ción $(\leftarrow$ tion -$)$ o ncia $(\leftarrow$ ntia-). Estos morfemas, de enorme rentabilidad en el español y entre los que no es fácil establecer distinciones notables de tipo semántico, sirven para formar nombres abstractos, pero conservan en cierta medida el significado de actividad o proceso del verbo sobre el que se construyen. En general, presentan el resultado de un desarrollo verbal («acción» + «efecto»).

Sobre su valor significativo dice J. Perrot ${ }^{7}$ : «La formation en -tio, qui fournissait des noms d'action du type "objectif", impliquant la realisation du procès dans un objet, a, comme - tus, développé un sens résultatif: le mot en - tio désignait alors l'objet produit par le procès et, lorsque la notion en cause était d'ordre abstrait, il pouvait se rapprocher du type en -mentum à sens résultatif». Por su parte Jesús Pena ${ }^{8}$, al hablar del sufijo - ment( $\leftarrow$ miento), señala: «Del sentido resultativo se puede pasar en las palabras concretas a la expresión del objeto resultado del proceso [...], y en las palabras abstractas a la expresión del acto por medio del cual se manifiesta el proceso". Y lo mismo sucede con el morfema — ncia, aunque éste puede crear, a diferencia de los otros dos, no sólo sustantivos verbales, sino también nombres de cualidad sobre una base adjetiva: elegancia, vehemencia, etcétera.

${ }^{5}$ Consideramos aquí sólo aquellas palabras que no están recogidas en los diccionarios o repertorios citados y de las que no tenemos noticia. Somos conscientes de la existencia de otros términos - ya documentados, o al menos registrados en el $D E C H$ - en los que se podría adelantar la datación, pero en principio prescindimos de ellos por razones metodológicas.

- Apoyo fundamental en la elaboración de este estudio ha sido el material informatizado, aún en prensa, de las Obras completas de San Juan de la Cruz que los PP. Carmelitas Descalzos (Roma-Salamanca) han puesto desinteresadamente a nuestra disposición. A ellos, pues, mi más profundo agradecimiento.

7 J. Perrot, Les dérivés latins en -ment et en -mentum, Paris 1961, p. 272. Cit. por Jesús Pena, La derivación en español. Verbos derivados y sustantivos verbales, Universidad de Santiago de Compostela, 1980, p. 108.

Ibidem, p. 117. 
Una vez delimitado el contenido semántico que aportan dichos sufijos a la forma verbal, hacemos un análisis pormenorizado de cada una de esas palabras 9 .

\section{Sustantivos en -miento}

AFERVORAMIENTO. -Escribe S. Juan en Llama, A, 1-16:

"Lo cual es mucho más que en la común unión de amor pasa, según el mayor afervoramiento del fuego, que aquí, como decimos, echa llama viva ${ }^{10}$.

Consiste, por tanto, en un afervoramiento del fuego" ${ }^{11}$. Si recurrimos a Aut. se recogen datos importantes:

Afervorarse: «lo mismo que afervorizarse, o enfervorizarse»

Afervorizar: «encender a otro en fervor, de donde tiene su origen».

Teniendo en cuenta la base latina Fervoren que significa ${ }^{12}$ :

- En su mayor parte son términos de una sola aparición. Cuando hay varios corresponden, por lo general, al mismo párrafo o capitulo, por lo que los contextos aparecen totalmente relacionados. No obstante daremos siempre cuenta de todos ellos.

${ }^{10}$ Manejamos para las citas las Obras completas de San Juan de la Cruz, edición de Lucinio Ruano de la Iglesia, Madrid, B.A.C., 1982.

"La formación del vocablo parece haber sido la siguiente:

Fervor (<Fervoren) $\rightarrow$ *Afervorar $\rightarrow$ Afervoramiento.

Para el estudio del procedimiento parasintético, vid. Yakov MALKIEL «Genetic analysis of word formation", en Current Trends in Linguistic, III, La Haya-Mouton, pp. 305-364, y Manuel Alvar y Bernard Pottier, Morfologia histórica del español, Madrid, Gredos, 1983, pp. 345-360.

12 Para establecer el significado de los términos latinos utilizamos generalmente el Dictionnaire latin-français de F. GAFFIOT, Paris, Hachette, 41 ed., 1986. En otras ocasiones-que aparecen indicadas - nos servimos de las acepciones que les otorga el $D E C H$. 
1. «bouillonnement, effervescence, fermentation» y 2. «chaleur, ardeur» -acepción que la palabra conserva hoy, pues el $D R A E$ lo define: 2. "calor intenso; como el del fuego o el del sol»-, observamos que lo que hace aquí nuestro escritor es crear una intensificación que raya prácticamente en lo hiperbólico. Se trata de un fuego intensísimo, que arde con una fuerza y calor extraordinarios, por eso mismo "echa llama viva». No hemos de olvidar que nos encontramos en el momento en que el alma se halla "transformada y reconcentrada en Dioss $)^{13}$.

DORMECIMIENTO. - Término neológico ${ }^{14}$ que aparece en Llama, A, 3-55:

"Y cuánto $\mathrm{El}<$ Dios $>15$ precia esta tranquilidad y dormecimiento o aniquilación de sentido, échase bien de ver en aquella conjuración tan notable y eficaz que hizo en los Cantares, diciendo:....".

En el $D E C H$ se recogen como derivados de dormir: adormecer [hacia 1250] y adormecimiento, aunque este último sin documentar. Dicha voz se halla ya en los escritos del Santo, pero, además Martín Alonso ${ }^{16}$ la registra con anterioridad en el Vocabulario de la lengua castellana y mexicana de Alonso de Molina ${ }^{17}$. Con todo, el neologismo persiste en esa variante con aféresis de a-. Tendremos, entonces, que comprobar cuál es el verdadero valor de adormecer, y así leemos en $A u t$ :

Adormecer 2: «metaphóricamente se dice de los afectos, que en cierto modo embotan y suspenden las operaciones y el sentido».

13 Llama, A, 1-14.

14 El proceso seguido en la creación de este sustantivo es evidente:

$$
\text { Adormecer } \rightarrow \text { Adormecimiento } \rightarrow \text { Dormecimiento. }
$$

is Se encierran en este signo $<>$ aquellas palabras imprescindibles para una mejor inteligencia del contexto ofrecido, tales como: sujetos pendientes, referencias pronominales, antecedentes en los relativos etc. De igual modo subrayamos siempre los términos y expresiones que en cada cita nos parecen más oportunos.

16 Martín Alonso, Enciclopedia del idioma, Madrid, Aguilar, 1982, (cito en adelante M. Alonso).

17 Alonso de Molina, Vocabulario de la lengua castellana y mexicana, Madrid 1944. Impreso en Méjico en 1571, colección de incunables americanos del Instituto de Cultura Hispánica. 
3: «vale también embotar los sentidos, o nervios embarazándoles el movimiento,...».

El dormecimiento supone, por tanto, un primer estado de anulación, de inmovilidad. La sublimación mística queda establecida de forma patente por medio de una progresión en el plano sintagmático: tiene su comienzo con la relajación del sentido ( = tranquilidad) y llega hasta la destrucción total del mismo (= aniquilación), pasando por una fase intermedia que es el dormecimiento.

\section{ANIQUILACIÓN}

DORMECIMIENTO

TRANQUILIDAD

ENCANDILAMIENTO. - En la Subida, 1, 8-3:

«Porque la causa del encandilamiento es que, como pone otra luz diferente delante de la vista, cébase la potencia visiva en aquella que está entrepuesta y no ve la otra, y como el apetito se le pone al alma tan cerca que está en la misma alma, tropieza en esta luz primera y cébase en ella, y así no la deja ver su luz de claro entendimiento, ni la verá hasta que se quite de en medio el encandilamiento del apetito's ${ }^{18}$.

1" Dice el $D E C H$ que encandilar "deslumbrar» deriva de candela «lumbre» con un influjo ulterior de la voz candil. Seria por consiguiente:

Candela $(-$ Candelam $) \rightarrow$ Encandilar $\rightarrow$ Encandilamiento.

El $D R A E$ no recoge en la actualidad el vocablo encandilamiento, pero sí lo hace $\mathrm{M}$. Alonso: "s. Xvi al XX. Acción de encandilar y su efecto". 
El mismo San Juan nos explica, de forma explícita, su significado, que así se ratifica por medio de $A u t$ :

Encandilar 1: «deslumbrar con la luz del candil o vela de noche, poniéndola de repente delante de los ojos del que nos viene al encuentro: lo que también por ampliación se atribuye y dice del resplandor vivo y ardiente de los rayos del Sol».

2: «metaphóricamente vale deslumbrar y halucinar con falsas apariencias, confundiendo el conocimiento".

Magnífica es la imagen creada por el místico: el apetito es una luz intensa que deslumbra, en este caso, no a la potencia visiva sino a la potencia cognoscitiva del alma racional, el entendimiento:

ceba y ciega
A) Encandilamiento real:
LUZ INTENSA - - - - . - - $>$ POTENCIA VISIVA
B) Metafónicamente:

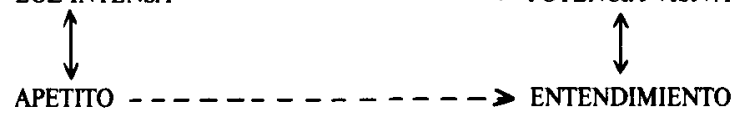

APETITO $=$ ENCANDILAMIENTO DEL ALMA

ENViamiento.-Tanto en Cántico, B, 25-7, como en Cántico, A, 16-7:

... «el cual < amor que Dios da a los ya perfectos>, con estas preciosas especias adobado < las virtudes $>$, tal esfuerzo y abundancia de suave embriaguez pone en el alma en las visitas que Dios la ${ }^{19}$ hace, que con

19 En Cántico, B: «... en las visitas que Dios le hace,...". 
grande eficacia y fuerza la hace ${ }^{20}$ enviar a Dios aquellas misiones o enviamientos de alabar, amar y reverenciar, etc., [...]; y esto con admirables deseos de hacer y padecer por Élı ${ }^{21}$.

Veamos su significado, en $A u t .:$

Enviar 1: «mandar que uno o alguna cosa vaya y se ponga en camino, u se remita para tal o tal parte».

2: "vale también dar, donar».

Es lógico, entonces, que enviamiento se haga en la escritura del Santo sinónima de emisión. En efecto, leemos en ese mismo diccionario:

Emissión: «el acto y obra de enviar y echar fuera alguna cosa».

El contenido del fragmento es ya evidente: las almas de los hombres perfectos, que gozan de la presencia divina, se entregan a Dios lanzándole dichas "emisiones o enviamientos de alabar, amar y reverencia, etc.».

Llegados a este punto nos enfrentamos con una cuestión de carácter textual, ya que este término presenta distintas variantes en los diferentes manuscritos. Tenemos la relación siguiente:

Cántico A: manuscrito $\mathrm{N}, \mathrm{y} \mathrm{A}^{\prime}$ : manuscrito $\mathrm{Rm}$ Embriagamientos.

Cántico A: manuscritos Ta, Ms y ed. br

Envahimientos.

Cántico B: manuscrito A

Envanimientos.

Cántico B: manuscrito $\mathrm{Bg}$ Embriamientos ${ }^{22}$.

${ }^{20}$ En Cántico, B: «...le hace enviar a Dios...».

${ }^{21}$ Etimológicamente la palabra enviar, sobre la que se construye el sustantivo, proviene -como indica el $D E C H$ - del latín tardio Inviare "recorrer (un camino)", a su vez derivado de Via «camino, ruta». Es decir:

Via $(<$ Viam $) \rightarrow$ Enviar $(<$ Inviare $) \rightarrow$ Enviamiento.

2. Las abreviaturas corresponden a los manuscritos siguientes: 
EMBRIAGAMIENTO ${ }^{23}$.-En la primera acepción de Aut . encontramos que embriagar significa etimológicamente «lo mismo que emborrachar», pero al registro de la escritura mística conviene mejor la segunda definición «metaphóricamente vale enajenar y transportar» significado que coincide en cierta manera con el actual dado por el $D R A E 2$ : «atontar, perturbar, adormecer»".

Embriagamiento es, en consecuencia, el acto de estar embriagado, es decir, «emborrachado", «enajenado», "perturbado», «transportado» por el amor divino. Francisco Rodríguez Marín $^{24}$ recoge también el vocablo, y con ese mismo sentido místico, en la obra del fraile franciscano Juan de Pineda ${ }^{25}$ :

... «este enagenamiento del alma con que saliendo fuera de sí se transpone toda en Dios, se llama embriagamiento de los charissimos y amantissimos...".

- N: Manuscrito de la Biblioteca Nacional núm. 17558 (fondo Pascual Gayangos).

- Rm: Manuscrito propiedad de la familia de A. Rodríguez Moñino.

- Ta: Manuscrito de las Madres Carmelitas de Tarazona.

- Ms: Manuscrito descubierto por José Muñoz Sendino, Biblioteca Nacional núm. 11086.

- A: Manuscrito de los Padres Carmelitas de Alba.

- Bg: Manuscrito de los Padres Carmelitas de Burgos.

- br: Corresponde a la edición Príncipe del Cántico, Bruxelas, 1627.

23 La formación es clara aquí:

Embriagar $\rightarrow$ Embriagamiento.

Embriagar procede del antiguo embriago «borracho» y éste a su vez, del latín vulgar Ebriacus, derivado de su sinónimo latino Ebrius; y su primera documentación se establece hacia 1400 , todo ello según el $D E C H$.

${ }^{24}$ Francisco Rodríguez MARÍn, op. cit.

${ }^{25}$ Juan DE PINEDA, Diálogos familiares de la agricultura christiana, Salamanca, Pedro de Adurça y Diego López, 1589, diálogo XXX-XVI. 
Más complejo resulta determinar la creación y significación de las otras tres variantes: envahimiento, envanimiento y embriamiento. Especialmente para la última parece difícil establecer la derivación sobre una base latina o romance, aunque se nos plantean varios supuestos:

1. Sobre el sustantivo brío, que forma parte también del corpus léxico de la obra, podria haberse originado el neologismo del modo siguiente:

$$
\text { Brío } \rightarrow^{*} \text { Embriar } \rightarrow \text { Embriamiento. }
$$

En Aut. observamos que brío en «ánimo, esfuerzo, valor, corage y grandeza de espíritu». Embriamiento tendría, entonces, el valor de acto realizado con ánimo, con fuerza y grandeza o vigor espiritual. Ello no debe extrañarnos demasiado si consideramos que en el contexto se dice:

... «asi este amor, [...], que grande eficacia y fuerza la hace enviar a Dios aquellas emisiones o enviamientos de alabar, amar y reverenciar, etc,..."

2. Por otro lado, hallamos en F. Gaffiot ${ }^{26}$ la voz Ebriare que significa "enivrer" y figuradamente "faire perdre la raison». Si embriamiento se ha creado a partir de ese verbo latino, debemos considerarlo sinónimo de embriagamiento porque entonces equivale, de igual forma, a «estar enajenado», «estar emborrachado», «haber perdido la razón». Claro está que, en este caso, tenemos que formular también un paso hipotético y, por tanto, tampoco seguro: la incorporación al término de una nasal implosiva $\mathbf{m}$, tal vez, por contagio con dicho vocable embriagamiento.

Respecto a las otras dos, se pueden presentar las siguientes hipótesis para su creación:

$$
\begin{aligned}
& \text { Vahido } \left.\rightarrow^{*} \text { Envahir(se }\right) \rightarrow \text { Envahimiento. } \\
& \text { Vano } \rightarrow \text { Vanear } \rightarrow^{*} \text { Envanear } \rightarrow \text { Envanimiento. }
\end{aligned}
$$

${ }^{26}$ Felix Gaffiot, op. cit. 
Según el $D E C H$ el término vahído fue váguido hasta el siglo XvIII y deriva probablemente de vago (<Vacuus) "vacio», ya que «el.que sufre un vahído tiene la sensación de no tener nada en la cabeza, de "perderla» como vulgarmente se dice». En verdad sucede así, en Aut:

Vaguido 1: «el desvanecimiento, o turbación de la cabeza, que pone a riesgo de perder el sentido, u de caer".

Envahimiento, tal como lo hemos considerado, sería entonces sinónima de envanimiento ya que volviendo de nuevo al $D E C H$ vemos que:

Vano procede del latín Vanus «vacio, hueco», «vano», documentado por primera vez en Berceo, y que Nebrija recoge en su Vocabulario españollatin $^{27}$ la voz vanea: «Nugor en palabras» (Nugor $=1$. «dire de balivernes, plaisanter», 2. «s'amuser à des bagatelles», 3. «conter des bourdes, se jouer de (alicui), - según F. Gaffiot-), pero es que además en gallego la expresión vanearse la cabeza significa también curiosamente «írsele la cabeza a uno"r.

En conclusión, si suponemos que fue de esta manera, tanto envahimiento como envanimiento equivaldrían a «desvanecimiento».

Todo ello conlleva varios inconvenientes:

1. Para los tres casos hay que suponer siempre una fase intermedia no documentada.

2. Nos preguntamos cómo, si hasta el siglo XVIII la palabra existente era váguido, la variante es envahimiento y no envaguimiento. La respuesta

${ }^{27}$ Elio Antonio De Nebrija, Vocabulario español-latino, Madrid, R.A.E., Castalia, 1951. 
es ahora sencilla: la voz ya existía en la época aunque con un sentido, en cierto modo, diferente ${ }^{28}$.

3. Sabemos que los verbos de la primera conjugación conservan su vocal temática - a- al recibir un sufijo en - miento-, mientras que la segunda y tercera presentan una - $\mathrm{i}-$, en opinión de Jesús Pena porque: «Diversos hechos de diacronía justifican la uniformación de la vocal temática. En los sustantivos en -ción-y -miento - es la inflexión de /e/ en /i/ ante la yod del sufijo" ${ }^{29}$. Entonces ¿por qué la variante es envanimiento en lugar de envaneamiento? Habría que contestar simplemente que el copista no es consciente de la utilización de esas reglas derivativas.

La explicación se presenta convincente en cuanto que esos neologismos tendrian un contenido demasiado poco místico en su valor no figurado y seria, por tanto, lícito creer que ello motivó la corrección de los copistas, quienes pensarian que se trataba de un error. Teniendo en cuenta las dificultades apuntadas arriba y que, además nos movemos en el terreno resbaladizo de las copias, nos inclinamos a pensar que se trata, en efecto, de un problema de mala interpretación del texto. Todo parece indicar la siguiente transmisión:

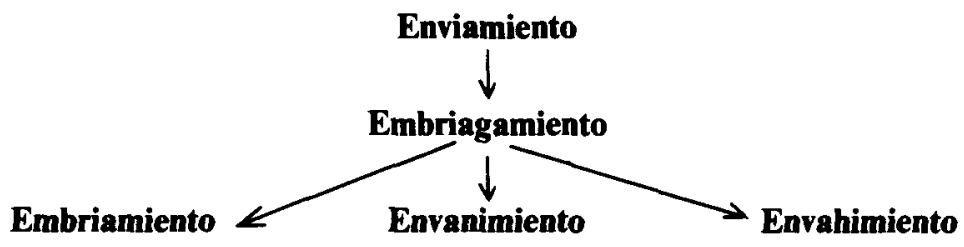

Las cuatro variantes suponen en el sentido que les hemos conferido una incompatibilidad contextual desde un punto de vista semántico. El vocablo compatible es, según veíamos, enviamiento (=emisión). Lo que ocurre es

2n Dice Covarr.:

Embair: «vale tanto como engañar persuadiendo con mentiras, con razones y cosas aparentes; trae origen del verbo imbuo, imbuis, que en su primera sinificación vale henchir algún vaso de qualque licor $y$, por translación, por instituyr, enseñar, porque el maestro hinche el entendimiento y la memoria de la doctrina y el embaydor de falsos conceptos, haziéndole creer lo que no es, y este desvanecimiento se llama embaymiento y embeleco".

20 Jesús Pena, op. cit., p. 128. 
que se produciría una primera sustitución de enviamiento por embriagamiento, tal vez porque el copista actuó demasiado deprisa. Un nuevo copista, sorprendido por ese término embriagamiento que conoce sólo en su uso no metafórico, lo sustituye por lo que él cree que sería embriamiento, inexistente, pero que al menos relacionaría con brío. Otros con la misma sorpresa lo cambian por envanimiento, también inexistente, pensando, quizá, en una formación del Santo, o por envahimiento que si existía ${ }^{30}$.

VIBRAMIENTO y PROVOCAMIENTO.-Ambos términos conviene estudiarlos juntos porque aparecen totalmente identificados. Hallamos vibramiento en varias ocasiones, todas en Llama de amor viva:

- En Llama, B, 3-10:

«A este talle entenderemos que el alma con sus potencias está esclarecida dentro de los resplandores de Dios; y los movimientos de estas llamas divinas, que son los vibramientos y llamaradas que habemos arriba dicho, no las hace sola el alma transformada en las llamas de el Espíritu Santo, ni las hace sólo él, sino él y el alma juntos, moviento él al alma, como hace el fuego al aire inflamado»" ${ }^{31}$.

- En Llama, B, 1-17:

... «y en aquel absorbimiento del alma en la sabiduria de el Espiritu Santo ejercita los vibramientos gloriosos de su llaman".

- En Llama, A, 3-10:

... «estos movimientos o vibramientos son los juegos y fiestas alegres que en el segundo verso de la primera canción decíamos que hacía el

30 Vid. nota 28.

31 En Llama, A el contexto es el mismo con ligeras variantes que aquí no interesan.

${ }^{32}$ También con variantes poco significativas para nuestro propósito en el correspondiente fragmento de Llama, A. 
Espíritu Santo en el alma, en los cuales parece que siempre la está queriendo acabar de dar la vida eterna».

Vibramiento es un sustantivo verbal construido sobre el latín Vibrare 1. «imprimer un mouvement vibratoire à quelque chose, agiter, brandir», "secouer», y según cabía esperar, significa lo mismo que vibración. En Aut.:

Vibración 2. «en la Estática es el movimiento igual a un lado, y otro, y libre de un cuerpo suspenso en el aire, con que se va acercando al punto de quietud en que descansa".

El $D E C H$, como es lógico, registra la palabra vibración -no así vibramiento-, pero establece su primera documentación en Aut., y además señala que del castellano vibrar no se tiene noticia hasta 1599 en el Guzmán de Alfarache; por tanto, juzgando, no desde nuestra perspectiva, sino desde la de la época, San Juan está siendo absolutamente innovador y creador en el aspecto léxico.

Analicemos ahora el otro neologismo ${ }^{33}$ relacionado con éste. De esa manera será posible reconstruir otra nueva imagen elaborada por el Santo, en este caso dentro del gran símbolo de la llama. En el mismo contexto señalado, Llama, A, 3-10 encontramos:

... «aquellos movimientos y llamaradas son como provocamientos que esté <el Espíritu Santo = Dios > haciendo al alma ${ }^{34}$ para acabarla de trasladar a su perfecta gloria, entrándola ya de veras en sín.

Provocare - voz latina compuesta de la preposición Pro más el verbo

${ }^{33}$ El sustantivo provocamiento se forma sobre el verbo provocar, derivado de voz. Asi:

$$
\text { Voz }(<\text { Vocem }) \rightarrow \text { Provocar }(<\text { Provocare }) \rightarrow \text { Provocamiento. }
$$

34 Esta cita corresponde a Obras completas de San Juan de la Cruz, edición de José Vicente Rodríguez y Federico Ruiz Salvador, Madrid, E.D.E., 3.` ed., 1988. En la edición de la B.A.C., el alma es sujeto de la oración en vez de objeto directo, sin embargo, una simple lectura del párrafo revela que tal hecho no es posible. 
Vocare «appeler»- significa 1. "appeler dehors, mander dehors, faire venir», 2. «appeler à, exciter, provoquer». Señala, así mismo Aut. para el correspondiente término castellano provocar:

1: «excitar, incitar, e inducir a otro a que execute alguna cosa».

4: «vale también facilitar, ayudar o mover».

5: «se usa freqüentemente por mover o incitar».

Es decir que, aquellos vibramientos consisten en llamadas o movimientos de excitación e incitación que Dios, en la figura del Espíritu Santo, hace al alma para ayudarla a que salga fuera de sí y vaya hacia Él; con ello se consumará de una manera definitiva la unión, ya cercana, pero que aún no se ha realizado. Por eso añade el escritor:

... «bien así como el fuego, que todos los movimientos y meneos que hace en el aire que en si tiene inflamado son a fin de llevarle al centro de su esfera, y todos aquellos vibramientos es porfiar por llevarlo, mas, porque el aire está en su esfera, no se hace; y así, aunque estos movimientos del Espíritu Santo son aquí encendidísimos y efícacísimos en absorber al alma en mucha gloria, todavía no acaba hasta que llegue el tiempo en que salga de la esfera del aire desta vida de carne y pueda entrar en el centro de su espíritu de la vida perfecta en Criston ${ }^{35}$.

Tanto vibramiento como provocamiento son, en conclusión, dos términos que el místico crea, basándose en las reglas derivativas, y a los que confiere un significado acorde con su etimología. No obstante, la grandeza reside en que esos vibramientos y provocamientos adquieren una significación muy concreta dentro del registro místico, que viene determinada, en gran medida, por la perfección de la imagen que el escritor elabora:

${ }^{35}$ Parte final de Llama, A, 3-10. 


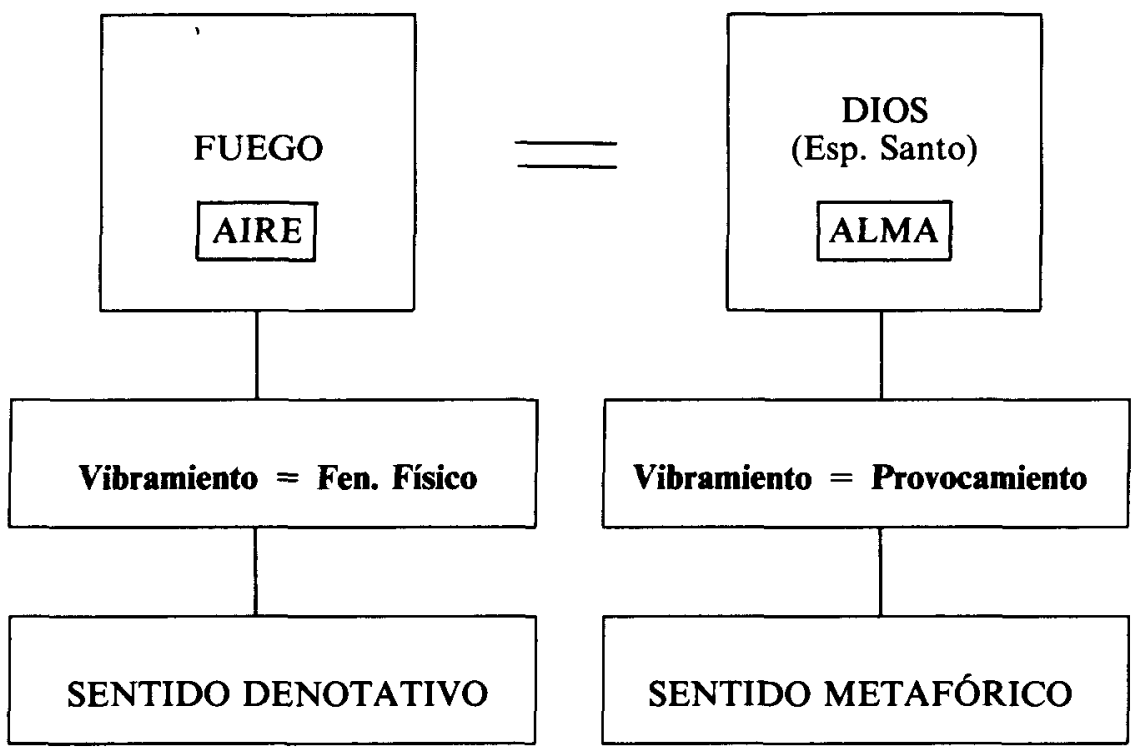

Por otra parte conviene añadir que estos dos términos, han persistido en la lengua, aunque el sufijo -miento fue sustituido en estas formas por el culto -ción: vibración y provocación (<Vibrationem y Provocationem). En esta línea parece que se confirma la idea sostenida por Jesús Pena ${ }^{36}$ : "Tuvieron que existir en mayor número formaciones en -miento- de procedencia latina desde los primeros momentos del idioma. Lo que sucede es que tales formaciones, lo mismo que gran parte de las creaciones romances, acabaron o acaban por ceder en el uso ante formaciones con otros sufijos, especialmente ante latinismos en -ción".

TRABUCAMIENTO.--En Llama, A, 2-9:

... «y entonces siente esta llaga el alma en deleite sobre todo encarecimiento, porque además de ser toda removida al trabucamiento y moción impetuosa de su fuego, en que es grande el ardor y derretimiento de amor,...".

36 Jesús Pena, op. cit., p. 163. 
Y, con ligeras diferencias en Llama, B, 2-9:

... «y entonces, al herir de este encendido dardo, siente la llaga el alma en deleite sobremanera, porque, demás de ser ella toda removida en gran suavidad al trabucamiento y moción impetuosa causada por aquel serafin, en que siente grande ardor y derretimiento de amor,...".

Trabucamiento es la acción de trabucar, verbo base que toma el castellano - según indica el $D E C H$ - del catalán o del occitano y que tiene el sentido de "volver lo de arriba abajo", derivado de buc "vientre», «capacidad interior de algo".

Parece, pues, que por su etimología habría que señalar dos semas fundamentales en esta palabra: [ + movimiento], [+ interioridad]. Sin embargo la voz trabucar desarrolló sólo la acepción de movimiento, como se puede observar en Aut:

Trabucar 1: «descomponer el orden, o colocación, que tiene alguna cosa, volviéndola lo de arriba abaxo, o interpolándola».

Con todo, los dos rasgos semánticos quedan expresados en el contexto gracias a la utilización del binomio: trabucamiento y moción. En el término moción se hallan los dos valores, incluso hoy día. En Aut.:

Moción 1: «la acción o passión, en virtud de la qual una cosa se mueve por sí, o es movida por otra».

3: «se toma también por la inspiración interior que Dios ocasiona en el alma, en orden a las cosas espirituales» ${ }^{37}$.

En efecto, ese brusco movimiento tiene lugar en lo más interior e íntimo del ser. Los agentes del mismo: el fuego (en Llama, A) y aquel serafin (en Llama, B) -reducibles a uno: un serafín con un dardo encendido en fuego

${ }^{37}$ El $D R A E$ recoge así mismo, entre otras, ambas acepciones. 
de amor divino-, causan en el alma, ya traspasada, una alteración total que "remueve» por completo su orden o configuración, al mismo tiempo que le comunican una profunda fuerza espiritual (trabucamiento + moción). Por eso añade San Juan, revelando su domino del idioma:

... «la herida fina y la yerba con que vivamente iba templando el hierro, siente el alma en la sustancia del espíritu, como en el corazón del alma traspasado" (Llama, A, 2-9).

... «siente <el alma > la herida fina y la yerba con que vivamente iba templando el hierro como una viva punta en la sustancia del espíritu, como en el corazón del alma traspasado" (Llama, B, 2-9).

ABSORBIMIENTO Y ABSORTAMIENTO.-En Cántico, A, 17-16:

"Y no se ha de entender que pierde alli el alma los hábitos de ciencia y totalmente las noticias de las cosas que antes sabia [...], sino que pierde el acto y memoria de las cosas en aquel absorbimiento de amor ${ }^{38}$.

En Aut. descubrimos dos hechos muy significativos:

1. Que allí aún no se recoge la palabra absorbimiento, lo que nos hace sospechar que se trate también de una forma nueva creada por el Santo.

2. Que el verbo absorber, además de la acepción denotativa, tiene un significado metafórico más acorde con el registro místico:

${ }^{38}$ El sustantivo verbal absorbimiento se encuentra en el $D E C H$, pero sin documentar. Es otra de las palabras que, deciamos, se han introducido en la lengua, prueba de ello es su aparición, también, en el $D R A E$. 
Absorver 2: "por translación vale embotar, y en cierta manera pasmar $\mathrm{y}$ ofuscary.

Marín Alonso corrobora ambas ideas ya que, por un lado, registra el uso de absorbimiento en San Juan de la Cruz, y por otro lo define como: «ensimismamiento, enajenación de las potencias del alma».

En los manuscritos N, Vd y $\mathrm{Va}^{39}$ aparece una variante de interés: «absortamiento de amor", término que no encontramos recogido en ningún diccionario de los citados. Se crea, como es lógico, sobre el verbo absortar ${ }^{40}$. Según Aut. consiste en: «suspender y arrebatar el ánimo, dexándole pasmado y admirado por lo inopinado y grande de algún objeto, o sucesso». Luego absortamiento es el acto de quedar pasmado, suspendido y arrebatado, en esta ocasión por la grandeza de amor que Dios infunde en el alma.

A diferencia de las variantes que veíamos al hablar del neologismo enviamiento, aquí el cambio no implica una incompatibilidad semántica contextual. No hubo, por tanto, mala interpretación por parte del copista. Éste no discierne la palabra que ha de transcribir, mas, empapado del espíritu místico de la obra, es capaz de sustituirla por otra derivada de un verbo conocido para él y que va a resultar, en cierto sentido, sinónima de la primera.

Para finalizar el estudio de los neologismos en —miento, resta el ánalisis de:

ObUMBRAMIENTO.-Proviene de Obumbramentum, voz originada sobre el verbo latino Obumbrare «ombrager, couvrir d'ombre», «obscurcir» pero también «couvrir, protéger».

De una manera precisa la define San Juan en el propio texto, Llama, A, 3-12:

«Para inteligencia de lo cual es de advertir que obumbramiento quiere decir hacimiento de sombra, y hacer sombra es tanto como amparar y hacer favores).

En consecuencia, el escritor se ciñe al contenido semántico de la palabra

${ }^{39}$ Cántico, A, manuscrito N. vid. nota 22.

Cántico, A, Vd y Cántico, A', Va: manuscritos de las Madres Carmelitas de Valladolid.

- Documentado hacia 1580 por el $D E C H$ en la obra de Santa Teresa de Jesús y Fray Luis de Granada. 
latina, trasladándolo de forma figurada a su escritura - a través de un símil que iguala las dos acepciones-, con lo que consigue dar cuerpo al concepto abstracto que desea transmitir.

Este sustantivo en -miento alterna en la obra con el correspondiente en -ción: obumbración, que es más frecuente según veremos.

\section{Sustantivos EN - CION}

Todos son cultismos tomados del latín. La mayoría de ellos no se incorpraron a nuestra lengua romance, como demuestra el hecho de no encontrarlos recogidos en ningún diccionario; alguno sí lo ha hecho, pero dado que no se conocen en la actualidad datos que los documenten en otros textos anteriores, podemos considerarlos neológicos en la obra de San Juan.

OBumbración.-Del latín Obumbrationem, tiene el mismo valor que expresábamos en obumbramiento:

«Para inteligencia de lo cual es de saber que obumbración quiere decir tanto como hacimiento de sombra, y hacer sombra es tanto como amparar, favorecer y hacer mercedes) (Llama, B, 3-12).

Sin embargo, es curioso que obumbración significa también en otros contextos «resplandor»:

«Porque estos resplandores por otro nombre se llaman obumbraciones» (Llama, B, 3-12).

Pero estos resplandores son inestimables mercedes y favores que Dios hace a el alma, porque éstas se llaman por otro nombre obumbraciones, y éstas aquí, a mi ver, son de las más altas que acá pueden ser en vía de transformación" (Llama, A, 3-12). 
Lo que ocurre es que estamos ante un juego de contrarios, es decir, ante una de las características paradojas en las que San Juan destaca igualmente como maestro ${ }^{41}$. Ello permite, precisamente, la fusión en ese mismo término de significados tan distintos. Así se explica en el parágrafo siguiente, Llama, B, 3-13:

«Para entender bien cómo sea este hacimiento de sombra de Dios u obumbraciones de grandes resplandores - que todo es uno-, es de saber que [...] la sombra de una luz será otra luz al talle de aquella luz"

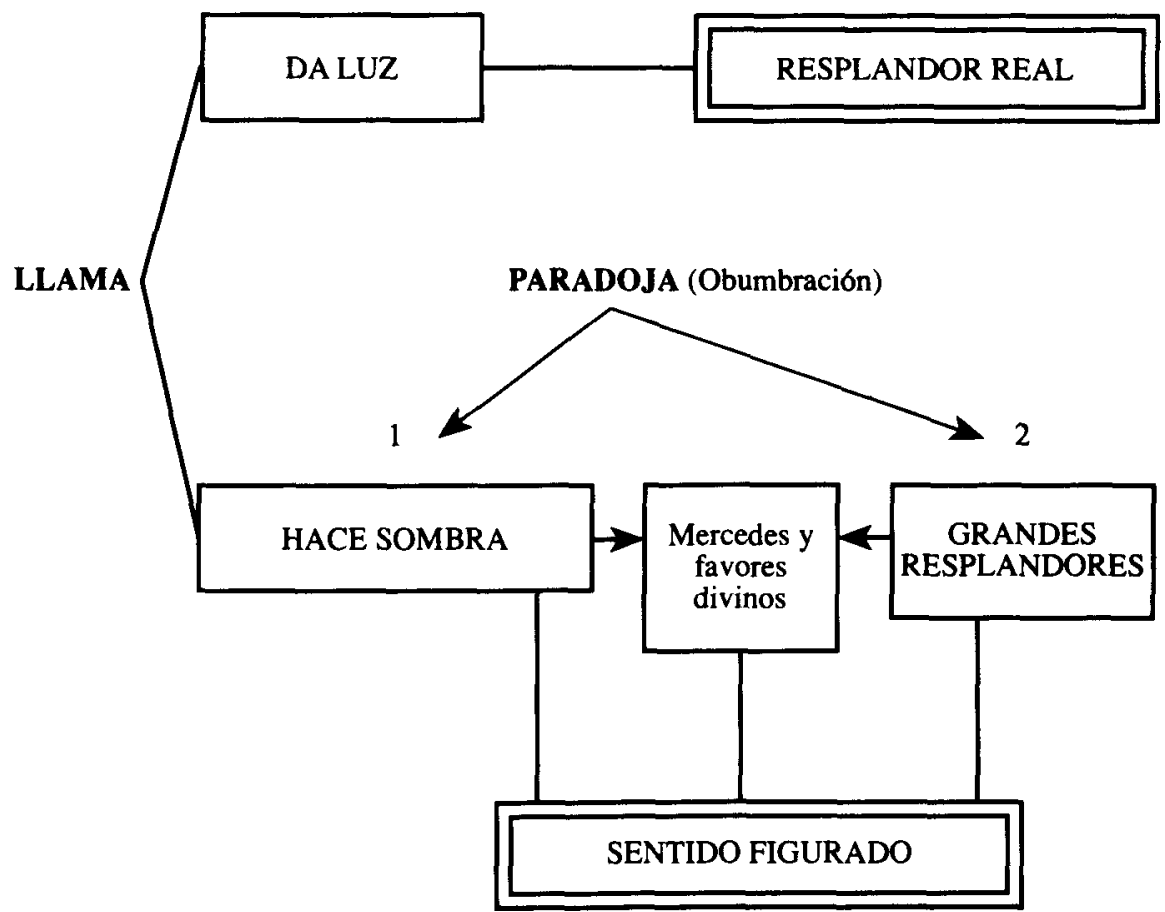

«Y por eso aquella gran merced que hizo Dios a la Virgen María en la concepción de el Hijo de Dios la llamó el ángel san Gabriel obumbración del Espiritu Santo, diciendo:..." (Llama, B, 3-12).

41 A este respecto vid. M." Jesús MANCho DuQue, «La expresión antitética en la obra de San Juan de la Cruz", en Actas del Congreso: la eclosión de la espiritualidad en la España del siglo XVI: aspectos literarios y lingüisticos de la mistica carmelitana, UNED Ávila, en prensa. 
Esta palabra, que aparece en las dos variantes: -miento y -ción, corrobora que entre esos sufijos no hay ninguna diferencia de matiz semántico. Ambas alternan porque significan lo mismo: «hacimiento de sombra" y "resplandor»" ${ }^{42}$. La distinción afecta sólo al eje diacrónico y al eje diastrático de la lengua ya que: «salvo pocas excepciones, -ción- se expande sobre verbos cultos y a partir de los siglos XV y XVI", mientras que «en líneas generales se puede afirmar que - miento-, de acuerdo con su forma popular, se desarrolla preferentemente sobre aquellos verbos que, formalmente, siguieron las evoluciones fonéticas propias de la lengua ${ }^{43}$.

Quizá sea esa la razón de que, como conviene a su carácter culto, exista en la obra una mayor frecuencia del neologismo obumbración que de su homólogo abumbramiento.

CORUSCACION.-Para el valor significativo de este término - que aparece una sola vez, concretamente en Noche Oscura -remito al estudio que de él hace $\mathbf{M}^{*}$ Jesús Mancho Duque al analizar el léxico relativo a este gran símbolo sanjuanista ${ }^{44}$.

El vocablo consiste en un cultismo que procede del latín Coruscationem «action de briller, étinceler», "fulguration», derivado verbal de Coruscare. El $D E C H$ no establece la primera datación del término coruscar hasta 1884 en el $D R A E$, sin embargo, ya M." Jesús Mancho en la obra citada, documenta dicha voz - unida a resplandecer-en un contexto puramente poético y culto: la II Égloga de Garcilaso de la Vega.

REDUNDACIÓN.-Resulta ser una variante de redundancia. En Cántico, A, 39-6:

... «porque esta parte sensitiva con sus potencias no pueden esencial y propiamente gustar los bienes espirituales [...]; sino por cierta redundancia de el espíritu reciben la recreación y deleite de ellos,...».

Es en el manuscrito $\mathrm{L}$ de Cántico, $\mathrm{A}^{\prime 45}$ donde encontramos la nueva forma neológica: redundación en lugar de redundancia. Los dos son sustantivos procedentes del verbo latino Redundare ( $>$ redundar) que, como indica

${ }^{42}$ Aunque en la edición de la B.A.C obumbramiento no presenta la segunda acepción, sí la encontramos, sin embargo, en la edición de la E.D.E: «obumbramientos o resplandores» (Llama, B, 3-13).

${ }^{43}$ Jesús Pena, op. cit., pp. 160 y 166.

- María Jesús MANCho DuQue, El simbolo de la noche en San Juan de la Cruez. estudio léxico-semántico, Universidad de Salamanca, 1982, p. 147.

${ }^{45}$ Manuscrito de las Madres Carmelitas de Loeches. 
el $D E C H$, significa «desbordarse», «abundar sumamente», "caer de rechazo sobre alguno" ${ }^{46}$.

El significado de ambos cultismos es, por tanto, el mismo porque tienen idéntico origen y tampoco existe divergencia semántica alguna entre los sufijos -ción y -ncia (cuando crea sustantivos verbales), como apuntábamos en la introducción a este trabajo. Se pueden definir como cacción y efecto de redundar", y redundar según la primera acepción que le confiere $A u t$., como: «rebosar, salirse alguna cosa de sus límites o bordes, por demasiadamente llenos y abundantes. Dícese regularmente de los líquidos».

Luego el término se aplica también aquí en sentido metafórico o figurado: el espíritu, totalmente colmado por el goce divino, se desborda igual que si de un líquido se tratase y cae sobre las potencias y sentidos corporales, deleitándolos de un modo indirecto.

ANIHILACIÓN y AJENACIÓN.-La primera aparece en Llama, B, 3-55:

«Y cuánto Él < Dios > precie esta tranquilidad y adormecimiento o anihilación de sentido échase bien de ver en aquella conjuración tan notable y eficaz que hizo en los Cantares,...».

Es una simple variante culta de aniquilación ${ }^{47}$. Procede del sustantivo Annihilationem, derivado a su vez del verbo latino Annihilare «réduire à néant; considérer comme rien». Aut. no recoge anihilación ${ }^{48}$, pero sí anihilar, de la que señala:

Anihilar: «lo mismo que Aniquilar. $Y$ aunque según su origen, que es de la voz Latina Nihil, se debiera escribir con $\mathbf{h}$, con todo esso generalmente se escribe y pronuncia Aniquiları ${ }^{49}$.

46 $\mathrm{El}$ proceso derivativo fue:

$$
\text { Undam }(>\text { onda })=\text { Redundare }(>\text { redundar }) \quad\left\{\begin{array}{l}
\text { Redundantiam (> redundancia) } \\
\text { Redundationem (> redundación) }
\end{array}\right.
$$

${ }^{47}$ Voz que se halla en el correspondiente contexto de Llama, A, 3-55.

${ }^{48}$ En la actualidad existe en la lengua como mero cultismo, por eso dice el $D R A E$ que es un término poco usado. Por su parte $\mathrm{M}$. Alonso lo caracteriza como voz del siglo xvi y lo documenta en PinedA, op. cit.

${ }^{4} \mathrm{El} D E C H$ nos explica ese cambio fonético como consecuencia de una ultracorreción. Observa que: «la forma medieval nichil, en lugar del clásico nihil, se debió a un esfuerzo por pronunciar la $h$ y evitar así la contracción en nil, reputada vulgar; en lugar de h se pronunció primero una chi griega o jota castellana, y luego $k »$. 
La segunda, ajenación, presenta una mayor complejidad. Consiste en una palabra que proviene del latín Alienationem 1. «aliénation, transmission (transport) d'une propriété a une autre», 2. «éloignement, désaffection», 3. "alienatio mentis, aliénation mentale».

Tiene en la obra de San Juan dos significados diferentes:

1. Dentro del mismo contexto anterior Llama, B, 3-55 encontramos, en el manuscrito $\mathrm{Sv}^{50}$, el término ajenación en lugar de aniquilación o anihilación:

«Y cuánto $\mathrm{El}<$ Dios $>$ precia esta tranquilidad $\mathrm{y}$ adormecimiento o ajenación de sentido,...».

Parece que, de las tres acepciones que F. Gaffiot propone para la palabra latina -según veiamos arriba-, es la tercera la que mejor conviene al contexto y que ajenación es aquí lo mismo que (enajenación ${ }^{31}$ o enajenamiento». A traves de Aut. podemos confirmar el hecho, puesto que iguala las voces alienación ( $>$ ajenación) y enajenación desde el punto de vista semántico:

Alenación 1: «lo mismo que Enajenación. Es voz latina, y de poco uso». Por otra parte descubrimos el verdadero valor significativo del neologismo, ya que, en primer lugar, este diccionario remite del término enajenación a enajenamiento, y éste último lo define, en una cuarta acepción, como: «metaphóricamente es la privación que experimentan los sentidos y potencias naturales y corpóreas, quando el alma arrebatada del espíritu y gracia sobrenatural, se eleva y sale fuera de sí, dexándolas como pasmadas y absortas").

La variante ajenación en lugar de aniquilación no impide, pues, que se mantenga la escala semántica gradatoria que en su momento ya comentábamos $^{52}$ : tranquilidad $=[+$ sosiego, relajación $]$, adormecimiento o dormecimiento $=[+$ inconsciencia $]$ y ajenación $o$ aniquilación (o anihilación) $=$

so Manuscrito de Sevilla, Biblioteca Nacional, 17950.

s1 También hallamos en la obra esta variante; concretamente en el manuscrito de las Madres Carmelitas de Córdoba: «enajenación de sentido».

52 Vid. dormecimiento. 
$=[+$ privación $]$. Entre ajenación y aniquilación sólo hay una diferencia de grado, puesto que la aniquilación conlleva además el sema [+ destrucción] que no tiene, por el contrario, el vocablo ajenación.

2. En Cántico, A, 14-27:

«Y, por cuanto el alma recibe esta sonora música no sin soledad y ajenación de todas las cosas exteriores, la llama "la música callada» y «la soledad sonora»; la cual dice que es su Amado»"

Y en Cántico, A, 25-10:

«Porque para este divino ejercicio interior es también necesaria soledad y ajenación de todas las cosas que se podrían ofrecer al alma, ...1 $\rangle^{54}$

En este caso el contenido significativo del término se corresponde con la segunda acepción que ofrece F. Gaffiot. Consiste en el topoi horaciano del Beatus ille, es decir, en el apartamiento y desapego de todo aquello que puede impedir el gozar — sólo- de la belleza de una vida interior, acorde con la armonía del universo. Claro está que, el Santo, trasciende el registro meramente ascético y traslada la idea a un plano mucho más profundo, el de la vivencia mística ${ }^{5 s}$.

MISERACION ${ }^{56}$.-Voz que encontramos también en dos obras distintas: Subida al Monte Carmelo y Llama de amor viva, pero aquí con idéntico sentido y en párrafos muy similares. Se trata exactamente de un cultismo neólogico que surge de una de las frecuentes traducciones que San Juan hace de la Biblia (en concreto del libro del Éxodo):

33 Idéntico contexto en Cántico, B, 14-27.

54 También sin modificaciones en Cántico, B, 16-10.

ss Vid. las declaraciones que hace el escritor de dichas canciones.

s6 Este vocablo se ha incorporado al registro léxico, lo recoge el $D R A E$ y $\mathrm{M}$. Alonso lo registra ya en V. SALvÁ: Nuevo diccionario de la lengua castellana, París, 8." ed., 1879. 
... «se postró Moisés muy aprisa en la tierra, diciendo: Dominator, Domine Deus, misericors et clemens, patiens et multae miserationis ac verax; qui custodis misericordiam in millia, etc.; que quiere decir: Emperador, Señor Dios, misericordioso y clemente, paciente y de mucha miseración y verdadero, que guardas la misericordia que prometes en millares $(E x$, 34, 6-7)» (Subida, 2, 26-4)

El sustantivo Miserationem, del cual procede, significa: 1. "commisération, pitié, compassion", pero el castellano se decantó por la variante con preposición Commiseratione ( $<$ Cum + Miseratione) $>$ conmiseración ${ }^{58}$ en lugar de la forma miseración para nuestra lengua.

\section{SUSTANTIVOS EN -CIA}

Dos son los que hemos recogido: flagrancia y renacencia.

FLAGRANCIA ${ }^{59}$.- Los contextos concretos en los que aparece son los siguientes, todos ellos en Cántico, A:

-En Cántico, A, 15-6:

... «las cuales < flores de virtudes que están en el alma > algunas veces es cosa admirable ver abrirse todas (causándolo el Espíritu Santo), y latino.

57 Vid. así mismo Llama, B, 3-4 y Llama, A, 3-4 donde el escritor traduce el mismo texto

58 Ya documentada por el $D E C H$ desde 1499 en Hernán Núñez.

5o Hemos de especificar, ante todo, que se trata de una palabra que no se puede considerar un neologismo en la obra del místico. El hecho de que aparezca en el presente estudio se debe a su estrecha relación con el resto de los sustantivos y, sobre todo, a que presenta un gran interés desde el punto de vista léxico-semántico.

Constituye una variante de fragancia en distintos manuscritos y el $D E C H$ la registra ya como tal variante en 1542 y, más tarde, en 1613 y en Quevedo. Además este nombre, frente a los otros, no deriva directamente del verbo flagrar sino del adjetivo flagrante. Consiste, por tanto, en un nombre de cualidad, y no de acción propiamente dicho. 
dar de sí admirable olor y fragancia [manuscritos S y Bz: flagrancia] en mucha variedad».

- En Cántico, A, 25-1:

"Viendo la esposa las virtudes de su alma puestas ya en el punto de su perfección, en que está ya gozando el deleite y suavidad y fragancia [manuscrito S: flagrancia] de ellas, [...], pide en esta canción a los ángeles y ministros de Dios que entiendan en apartar de ella todas aquellas cosas que pueden derribar y ahajar la dicha flor y fragancia [manuscritos S y Ms: flagrancia] de sus virtudes».

- En Cántico, A, 26-5:

... «y aspirar "por" el alma es hacer Dios toque en las virtudes y perfecciones que ya le son dadas, renovándolas y moviéndolas de suerte que den de sí admirable fragancia [manuscritos S, Ms y Bz: flagrancia] y suavidad".

- En Cánitico, A, 26-10:

"Y ésta es la condición de el Esposo, pacer al alma entre la fragancia [manuscritos S y Ms: flagrancia] de estas flores < de virtudes y dones y perfecciones $>1{ }^{60}$.

* Cántico, A, manuscrito S: manuscrito de las Madres Carmelitas de Sanlúcar.

Cántico, $\mathrm{A}^{\prime}$, manuscrito $\mathrm{Bz}$ : manuscrito de Baeza, Biblioteca Nacional núm. 8795.

Cántico, A, manuscrito Ms: vid. nota 22. 
Se observa que en todos estos casos el término compatible desde una perspectiva semántica es, sin duda, fragancia. Resulta obvio que esas flores, aunque representen a las virtudes del alma, exhalarán siempre olor o fragancia, y no flagrancia. Ahora bien, ¿a qué se debe la mutación de flagrancia en vez de fragancia que, según indicábamos arriba, no es exclusiva de los escritos del Santo?

Es evidente que flagrancia pudo producirse por una simple disimilación de líquidas, pues el actual fragancia era antiguamente fragrancia. Dice $A u t$.:

Fragrancia 1: «olor suave y delicioso que recrea el sentido. Es voz puramente latina y, algunos dicen Fragancia; pero con menos propiedad».

No obstante conviene tener en cuenta también que aunque:

- El cultismo flagrancia no se incorpora al corpus léxico del castellano hasta 1848 en el Diccionario de Ramón Joaquín Domínguez ${ }^{61}$, quien lo define como «cualidad de lo flagrante», es decir, de lo que arde.

- Y que, por otra parte, todavía en 1870 en el Diccionario de Marty Caballero ${ }^{62}$ encontramos:

Flagrancia: «fragancia».

Sin embargo, no podemos olvidar que en latín existe - junto a Fragrare «exhaler fortement une odeur» y su derivado Fragrantia- el verbo Flagrare 1. «brûler, être en feu», 4. "être ardent", 5. «[poét.] enflammer d'amour", de donde procede el sustantivo Flagrantia ("vive chaleur, embrasement» y en forma figurada (sentiment ardent»), y en castellano: flagrar, documentado en el $D E C H$ por primera vez en Villamediana, y flagrante, primera datación en 1444 en Juan de Mena, Laberinto de Fortuna: "curvas flagrantes» (= «ardientes»).

Si se considera la similitud de significantes entre ambas familias léxicas latinas y que los valores figurados constituyen una constante en la escritura

" Ramón Joaquín Domínguez, Diccionario nacional o gran diccionario clásico de la lengua española, Madrid. Establecimiento tipográfico de Mellado, 1848. La Real Academia no lo introduce hasta 1899 , en la decimo tercera edición de su Diccionario, Madrid, Imprenta de los Sres. Hernando y Cía.

62 Marty Caballero, Diccionario de la lengua castellana, Madrid, Manuel Rodriguez editor, 1870. 
mistica y, muy especialmente, en San Juan —siendo la llama una de sus imágenes más significativas - no sería dificil pensar en una errónea interpretación de los copistas. Flagrancia (<Flagrantiam) consistiria entonces en una creación motivada, tanto por hechos fonéticos, como por cuestiones de significado y equivaldría a un cultismo semántico con el sentido de «calor vivo, intenso".

Además curiosamente descubrimos que ya en Santa Teresa de Jesús los dos semas [+ calor], [+olor] se interrelacionan, de alguna manera, en torno a la voz fragancia:

$\ldots \ll<$ el alma $>$ entiende una fragancia, como si en aquel hondón interior estuviese un brasero adonde se echasen olorosos perfumes; ni se ve la lumbre ni dónde está; mas el calor y humo oloroso penetra toda el alma, y aun hartas veces participa el cuerpo" (Moradas, IV, 2-6).

Todo ello parece evidenciar una hipotética relación entre ambas palabras: Fragrantiam ( $>$ fragancia) y Flagrantiam ( $>$ flagrancia), lo que podría explicar la variante y el contexto citado de la Santa.

RENACENCIA.-Mucho menos compleja resulta esta forma ${ }^{63}$ que aparece en una sola ocasión, Subida, 2, 5-5:

... $\ll<$ pueden transformarse en Dios $>$ los que, renaciendo por gracia, muriendo primero a todo lo que es hombre viejo, se levantan sobre sí a lo sobrenatural, recibiendo de Dios la tal renacencia y filiación, que es sobre todo lo que se puede pensarm.

${ }^{63}$ Las fases consecutivas hasta la creación de este vocablo han sido:

Nacer $(<$ Nascere $) \rightarrow$ Renacer $(<$ Renascere $) \rightarrow$ Renacencia.

El $D E C H$ señala que en el siglo XIII se documenta dialectalmente el término nacencia, aunque ya Nebrija registra sólo nacimiento. 
La base rénacer según $A u t$. significa:

1: «volver a nacer, o nacer de nuevo".

2: «en el sentido moral vale alentar a nuevo ser espiritual: y assí se dice, que se renace por el Baptismo».

Por tanto renacencia supone aqui el acto de nacer de nuevo a la gracia espiritual. Debajo de ello subyace toda una tradición mitológica: el fin de un periodo y el inicio de otro, la perfección de los orígenes, el mito del ave fénix, etc. El hecho de renacer implica, en este caso, que sucumbe el hombre viejo, con todas sus flaquezas, y cobra vida el hombre nuevo, un ser regenerado espiritualmente capaz de elevarse y alcanzar la cima: la unión con Dios.

\section{Algunas ADVERTENCIAS finAles}

Trás el análisis de todos estos sustantivos conviene establecer ciertas consideraciones:

1.- Hemos de tener en cuenta, en primer lugar, que nuestro trabajo es limitado por razones de brevedad. Cabe señalarse un número mucho mayor de formaciones neológicas en la obra de San Juan: formas verbales, adjetivas, adverbiales y también algunos sustantivos de carácter adjetival, es decir, cuya base no es un verbo sino un adjetivo; objeto todo ello de otros posibles estudios.

Es precisamente tal variedad y riqueza la que permite destacar al Santo como gran innovador de la lengua de su tiempo, tanto en el plano léxico como en el conceptual.

2.- La mayor parte de las creaciones se producen en el campo de la teología mística, constituyendo auténticos tecnicismos (así ocurre, por ejemplo, en coruscación, obumbración, vibramiento, provocamiento, etc, o en neologismos como encandilamiento donde aflora la teoría del rayo de tiniebla), 
aunque se imbrican así mismo aspectos antropológicos (como en redundación, dormecimiento, etc), e incluso psicológicos (en absortamiento, embriagamiento, etc.). Pero, ¿por qué todas se originan en este terreno? Porque en verdad es ahí donde a San Juan la lengua le resulta estrecha, insuficiente y la inefabilidad le obliga a ampliar el léxico. En principio lo que el escritor pretende es hacerse entender, transmitir a los demás unas vivencias religiosas no comunes. Esa es la causa que le lleva a la necesidad de formar vocablos nuevos partiendo de otros ya existentes, bien sean romances o latinos.

3.- Observamos que las voces estudiadas aparecen en su mayoría repartidas entre la Llama de amor viva y el Cántico espiritual. Únicamente cuatro se pueden localizar en otras obras. La distribución es la siguiente:

Llama de amor viva: afervoramiento, dormecimiento, vibramiento, provocamiento, trabucamiento, obumbración, su variante obumbramiento, ajenación (sólo como variante textual), miseración (que también se encuentra en Súbida) y anihilación.

Cántico espiritual: enviamiento (y las variantes embriagamiento, embriamiento, envahimiento y envanimiento), absortamiento, redundación, flagrancia y ajenación. Todas ellas variantes en los diferentes manuscritos, a excepción de la primera y la última.

Subida al monte Carmelo: encandilamiento, miseración y renacencia.

Noche oscura del alma: sólo una: coruscación.

En efecto, los neologismos se producen, en línea general, en la última fase del proceso místico, cuando el alma goza ya de los deleites divinos. Este punto además de relacionarse de nuevo con el problema de la inefabilidad, explica el mayor porcentaje de ellos en Llama de amor viva y en Cántico espiritual, mientras que en las otras dos —centradas más bien en fases anteriores- la frecuencia es menor.

Por otro lado no debe de extrañarnos que, de los términos recogidos, todos aquellos que son variantes de manuscritos, excepto ajenación, se hallan en Cántico espiritual, ya que es de esta obra de la que se conserva más número de copias y, por tanto, en la que hay una mayor divergencia textual.

4.- Se percibe con claridad un notable predominio en la obra del Santo 
de las creaciones populares en -miento sobre las cultas en -ción ${ }^{64}$. El carácter popular y culto, respectivamente, de esos morfemas, ya apuntado - según dijimos- por Jesús Pena, se confirma a través de un estudio, de los términos analizados en este trabajo, por medio del Laterculi vocum latinarum $^{65} \mathrm{y}$ del Thesaurus ${ }^{66}$. Dicho examen revela la no presencia en latín de los sustantivos verbales correspondientes en -mentum (todos son, por tanto, - a excepción de obumbramiento (<Obumbramentum) - derivados romances), mientras que las voces en -ción tienen siempre su correlato latino. Parece, en principio pues, que existe en el escritor una tendencia hacia lo popular, sin embargo, no debemos engañarnos: ésta se da sólo en cuanto a la formación de palabras nuevas, ya que un cómputo general de los términos sanjuanistas ( 84 acabados en -miento frente a 204 en -ción) descarta el que podamos mantener tal inclinación y tengamos que señalar, junto con Pena, una mayor presencia en esta época del sufijo culto, que debió de desbancar al popular.

* Así como un rendimiento muy bajo del sufijo $\rightarrow$ ncia en tales creaciones.

${ }^{65}$ Otto Gradenwitz, Laterculi vocum latinarum Leipzig, Verlag von S. Hirzel, 1904.

to Thesaurus linguae latinae, Lipsiae in aedibus B.B. Teubneri, 1900. 